\title{
The Melanocortin-3 Receptor Is Required for Entrainment to Meal Intake
}

\author{
Gregory M. Sutton, ${ }^{1}$ Diego Perez-Tilve, ${ }^{3}$ Ruben Nogueiras, ${ }^{3,4}$ Jidong Fang, ${ }^{5}$ Jason K. Kim, ${ }^{6}$ Roger D. Cone, ${ }^{7}$ \\ Jeffrey M. Gimble, ${ }^{2}$ Matthias H. Tschöp, ${ }^{3,4}$ and Andrew A. Butler ${ }^{1,2}$ \\ ${ }^{1}$ Neuropeptides Laboratory, ${ }^{2}$ Clinical Nutrition Research Unit, Pennington Biomedical Research Center, Louisiana State University System, Baton Rouge, \\ Louisiana 70808, ${ }^{3}$ Department of Pharmacology, German Institute of Human Nutrition Potsdam-Rehbruecke, 14558 Nuthetal, Germany, ${ }^{4}$ Department of \\ Psychiatry, Obesity Research Centre, University of Cincinnati, Cincinnati, Ohio 45226, Departments of ${ }^{5}$ Psychiatry and ${ }^{6}$ Cellular and Molecular Physiology, \\ Pennsylvania State University College of Medicine, Hershey, Pennsylvania 17033, and ${ }^{7}$ Center for the Study of Weight Regulation and Associated Disorders \\ and the Vollum Institute, Oregon Health \& Science University, Portland, Oregon 97239-3098
}

Entrainment of anticipatory activity and wakefulness to nutrient availability is a poorly understood component of energy homeostasis. Restricted feeding $(\mathrm{RF})$ paradigms with a periodicity of $24 \mathrm{~h}$ rapidly induce entrainment of rhythms anticipating food presentation that are independent of master clocks in the suprachiasmatic nucleus (SCN) but do require other hypothalamic structures. Here, we report that the melanocortin system, which resides in hypothalamic structures required for food entrainment, is required for expression of food entrainable rhythms. Food anticipatory activity was assessed in wild-type (WT) and melanocortin-3 receptor-deficient $(M c 3 r-/-)$ C57BL/J mice by wheel running, spontaneous locomotory movement, and measurement of wakefulness. WT mice housed in wheel cages subject to RF exhibited increased wheel activity during the $2 \mathrm{~h}$ preceding meal presentation, which corresponded with an increase in wakefulness around meal time and reduced wakefulness during the dark. WT mice also exhibited increased $x$-and $z$-movements centered around food initiation. The activity-based responses to RF were significantly impaired in mice lacking Mc3r. RF also failed to increase wakefulness in the $2 \mathrm{~h}$ before food presentation in $M c 3 r-1-$ mice. Food entrainment requires expression of Neuronal PAS domain 2 (Npas2) and Period2 (Per2) genes, components of the transcriptional machinery maintaining a clock rhythm. Analysis of cortical gene expression revealed severe abnormalities in rhythmic expression of clock genes (Bmal1, Npas2, Per2) under ad libitum and RF conditions. In summary, $\mathrm{Mc} 3 \mathrm{r}$ are required for expression of anticipatory patterns of activity and wakefulness during periods of limited nutrient availability and for normal regulation of cortical clock function.

Key words: circadian rhythms; POMC; proopiomelanocortin; entrainment; waking; sleep; food; neuropeptide; arousal; rhythm

\section{Introduction}

Energy homeostasis as it relates to obesity is classically viewed from the perspective of balancing energy intake with expenditure (Hill, 2006). Hypothalamic melanocortin neurons are essential for energy homeostasis, integrating neural and neuroendocrine signals of energy status to affect ingestive behavior and energy expenditure (EE) (Cone, 2005, 2006). Melanocyte-stimulating hormones $(\alpha-, \beta$ - and $\gamma-\mathrm{MSH})$ are produced by post-translational processing of proopiomelanocortin in neurons residing in the arcuate nucleus of the hypothalamus (ARC) (Cone, 2005, 2006). Central administration of $\alpha$-MSH reduces appetite and increases EE (Cone, 2006). Another population of ARC neurons synthesize

\footnotetext{
Received July 30, 2008; revised Sept. 19, 2008; accepted 0ct. 14, 2008.

This work was supported by the Pennington Biomedical Research Foundation (A.A.B., J.M.G.), and National Institutes of Health Grant DK073189 to A.A.B. A.A.B. and J.M.G. are partially supported by a Clinical Nutrition Research Unit Center Grant (1P30 DK072476) entitled "Nutritional Programming: Environmental and Molecular Interactions" sponsored by National Institute of Diabetes and Digestive and Kidney Diseases. We appreciate the technical assistance of Brian Goh, Emily Meyer, and Xiying Wu in performing RNA preparations and qRT-PCR analyses.

Correspondence should be addressed to Andrew A. Butler, Pennington Biomedical Research Center, 6400 Perkins Road, Baton Rouge, LA 70808. E-mail: butleraa@pbrc.edu.

DOI:10.1523/JNEUROSCI.3615-08.2008

Copyright $\odot 2008$ Society for Neuroscience $\quad 0270-6474 / 08 / 2812946-10 \$ 15.00 / 0$
}

the melanocortin antagonist/inverse agonist agouti-related peptide (AgRP) (Cone, 2005, 2006). Central infusion of AgRP acts oppositely, increasing appetite, reducing EE and inhibiting actions of centrally administered MSH (Rossi et al., 1998). AgRP also has long term effects on EE involving inverse agonism (Tolle and Low, 2008).

The regulation of energy homeostasis by melanocortins involves two melanocortin receptors (Mc3r, Mc4r) (Butler, 2006; Cone, 2006). While the Mc4r has been interrogated intensively for the treatment of obesity, the homeostatic functions of $\mathrm{Mc} 3 \mathrm{r}$ have remained enigmatic. Mc3r knock-out $(\mathrm{Mc} 3 \mathrm{r}-\mathrm{/}-)$ mice exhibit exacerbated diet-induced obesity associated with abnormalities in physical activity and nutrient partitioning (Chen et al., 2000; Butler, 2006; Sutton et al., 2006; Ellacott et al., 2007). However, satiety and the autonomic and neuroendocrine pathways affecting EE are primarily regulated through Mc4r (Marsh et al., 1999; Chen et al., 2000; Butler et al., 2001; Rahmouni et al., 2003; Fekete et al., 2004; Zhang et al., 2005). The regulation of energy homeostasis by $\mathrm{Mc} 3 \mathrm{r}$ thus involves mechanisms not classically associated with obesity.

Maintaining circadian rhythms in energy consumption and expenditure is essential for energy homeostasis (Staels, 2006). At 
a cellular level, transcription factors involved in regulating energy metabolism also regulate the expression of critical clock genes (Duez and Staels, 2007; Liu et al., 2007). Neuroanatomically, the hypothalamic centers involved in energy homeostasis such as the dorsomedial and ventromedial hypothalamus (DMH, VMH) are also required for an anticipatory pattern of behavior in response to limited nutrient availability (Chou et al., 2003; Gooley et al., 2006; Fuller et al., 2008). Collectively, these observations suggest that the systems governing rhythmic patterns in energy homeostasis in response to caloric intake may respond to caloric cues through common pathways.

Several observations led us to hypothesize that food entrainment may be a homeostatic output of melanocortin neurons acting through Mc3r. C57BL/6J (B6) Mc3r-/- mice exhibit abnormal daily patterns of feeding behavior (Butler, 2006). Dense expression of $\mathrm{Mc} 3 \mathrm{r}$ mRNA is also observed in hypothalamic centers involved in maintaining circadian rhythms (Roselli-Rehfuss et al., 1993), including the DMH, which may be critical for food entrainment (Gooley et al., 2006; Fuller et al., 2008). Moreover, melanocortin neurons are regulated by meal ingestion (Johnstone et al., 2006; Singru et al., 2007). Here, we present further evidence supporting this hypothesis, showing that $\mathrm{Mc} 3 \mathrm{r}$ are required for entrainment of anticipatory behavior to feeding time. Melanocortin neurons may therefore link neural systems governing energy homeostasis with those affecting entrainment to food availability.

\section{Materials and Methods}

Experimental animals. The Pennington Biomedical Research Center Institutional Animal Care and Use Committee approved all experiments. Mc3-/- and Mc4r-/- were obtained from heterozygote-byheterozygote crosses in colonies maintained at the Pennington Biomedical Research Center, as described previously (Sutton et al., 2006). KKAy were purchased from the Jackson Laboratory. Mice were maintained on a $12 \mathrm{~h} \mathrm{light/dark} \mathrm{period} \mathrm{with} \mathrm{lights} \mathrm{on} 0600-1800 \mathrm{~h}$; corresponding to Zeitgeber Time (ZT) $0-12$. Percentage body fat was estimated by measuring FM and fat-free mass using nuclear magnetic resonance (NMR; Bruker Mice Minispec NMR Analyzer, Bruker Optics). Low fat diet (Research Diets \#12450B) was purchased from Research Diets.

Physical activity and energy expenditure. For experiments assessing activity using running wheels, mice aged $\sim 2$ months were acclimated for 1 month to clear plastic caging with running wheels (MiniMitter). Wheel running data collected using Vital View Data Acquisition System was analyzed using Microsoft Excel. Estimates of ad libitum (AL) food intake were measured from preweighed amounts.

For experiments examining anticipatory activity and EE, mice were housed in a 16 chamber Comprehensive Laboratory Animal Monitoring System (CLAMS) (Columbus Instruments) as described previously (Trevaskis and Butler, 2005). The area under the curve (AUC) for the respiratory exchange ratio (RER) data were calculated using 0.7 as the baseline and data averaged into $1 \mathrm{~h}$ bins.

Ambulatory activity in the $x$ - and $z$-axes was evaluated using an OPTO-M3 sensor system (Columbus Instruments). Physical activity and EE data were collected over a $10 \mathrm{~d}$ period, with chambers disassembled for maintenance every $3 \mathrm{~d}$. After $7 \mathrm{~d}$ of lead in data/acclimation, mice were given $4 \mathrm{~h}$ access to $2.5 \mathrm{~g}$ of a powdered form of low fat diet (Research Diets; 12450B).

Wakefulness, nonrapid and rapid eye-movement sleep. Sleep state and wakefulness were analyzed at the Penn State Diabetes \& Obesity Mouse Metabolic Phenotyping Center. Briefly WT $(n=9)$ and $M c 3 r-/-$ mice $(n=6)$ were continuously fed with the regular lab chows during weeks of sleep analysis. The recording system consisted of a personal computer with an 12-bit analog-to-digital (AD) converter (Model PCI-6023E, National Instruments), and a Grass Model 12 Neurodata amplifier system (Grass Instrument Division of Astro-Med). The electroencephalographic (EEG) and electromyographic (EMG) signals were amplified with 12A5 amplifiers. The one-half cutoff frequencies in EEG recordings for low and high frequencies were at 0.5 and $35.0 \mathrm{~Hz}$, respectively. The EMG signals were filtered with one-half cutoff for low and high frequencies at 100 and 10,000 Hz, respectively. The data collection was controlled by the computer and a computer program (SleepWave, developed by Dr. Jidong Fang, Department of Psychiatry, University of Cincinnati, Cincinnati, $\mathrm{OH})$. The $\mathrm{J} 10$ outputs from the $12 \mathrm{~A} 5$ amplifiers were fed into the $\mathrm{AD}$ converter and displayed on the computer monitor. The EEG and EMG data were saved to the hard disk drive. Wakefulness data are presented in minutes per hour.

Central AgRP infusions. Eight-week-old male B6 mice were purchased from Jackson Labs and group housed in our animal facility. Mice were maintained in $12 \mathrm{~h}$ light/dark period (lights on 0600-1800). Mice were anesthetized with ketamine ( $86 \mathrm{mg} / \mathrm{kg}$, i.p. $) /$ xylazine $(12.9 \mathrm{mg} / \mathrm{kg}$, i.p.). A stainless steel cannula (Brain infusion kit, Alzet Durect) was placed in the right lateral cerebral ventricle and fixed to the skull with dental cement and two stainless steel screws. The stereotaxic coordinates used were as follows: anteroposterior, $-0.80 \mathrm{~mm}$; lateral, $0.14 \mathrm{~mm}$; dorsoventral, $-3.50 \mathrm{~mm}$, from bregma. The intracerebroventricular cannula was connected through a polyvinyl tube to an osmotic minipump containing either the $C$ terminus of mouse AgRP $\left(\mathrm{AgRP}^{82-131}\right)$ purchased from Phoenix Pharmaceuticals), or vehicle (artificial CSF, ACSF). The osmotic minipumps (model 1002, Alzet Durect) were implanted subcutaneously in the interscapular space, with infusion lasting $14 \mathrm{~d}$. The skin was sutured and the animals received a single dose of buprenorphin $(0.28 \mathrm{mg} / \mathrm{kg}$, s.c.; Buprenex; Reckitt Benckiser Healthcare). Mice were administered a constant infusion of AgRP ${ }^{82-131}(0.05 \mathrm{nmol} / \mathrm{d})$ or ACSF. Mice were allowed to eat ad libitum for $3 \mathrm{~d}$; measurement of food intake during this time demonstrated the predicted increase of food intake associated with AgRP ${ }^{82-131}$ treatment which was statistically significant on day $3(6.1 \pm$ 0.1 compared with $4.8 \pm 0.3 \mathrm{~g}, p<0.01)$. The AgRP ${ }^{82-131}$ and ACSF groups were then subdivided into two groups. One group was subjected to restricted feeding (RF), receiving $2.5 \mathrm{~g}$ of a low fat diet between 1300 and $1700 \mathrm{~h}$. A second group of mice was given $4.7 \mathrm{~g}$ of food provided at $1800 \mathrm{~h}$. Mice grouped into time points were killed every $6 \mathrm{~h}(n=5-6$ per time point and treatment) and forebrain extracted for the analysis of clock gene expression.

Cortical forebrain isolation. Brains were removed from mice at $6 \mathrm{~h}$ intervals to cover a $24 \mathrm{~h}$ time period and snap frozen in isopentane (Sigma). On the day of tissue collection, which occurred after $7 \mathrm{~d}$ of RF, mice were not fed. The hindbrain was removed and the forebrain transferred to a cryostat. One hundred micron sections were shaved off of the forebrain until a rostral section roughly, -2.92 interaural/0.88 bregma was reached. Using a punch tool with a 0.5 interior diameter needle all of the cortical forebrain was removed, being careful not to isolate tissue from hippocampal, thalamic, or hypothalamic regions.

Gene expression. Total RNA from the cortex was isolated using TRI Reagent (Molecular Research Centre), and reverse transcribed using Superscript III reverse transcription system (Invitrogen). Oligonucleotide primers (Integrated DNA Technologies) were designed using Primer Express 2.0 software (Applied Biosystems). Quantitation of target gene mRNA used GAPDH as a reference was performed in 96 or 384 well plates using SYBR Green, or Taqman Universal, PCR Master Mix (Applied Biosystems) and an ABI PRISM 7900 HT Sequence Detection System (Applied Biosystems). Sequences of primers and probes used for expression analyses were as follows: mus_Npas2_fwd acgcagatgttcgagtggaaa, mus_Npas2_rev cgcccatgtcaagtgcatt, mus_Bmal1/Arntl_fwd aaccttcccgcagctaacag, mus_Bmal1/Arntl_rev agtcctctttgggccacctt, mus_Per2_fwd AGAACGCGGATATGTTTGCTG, mus_Per2_rev ATCTAAGCCGCTGCACACACT, mus_GAPDH_fwd tccgtgtcctacccccaatg, mus_GAPDH_rev gagtgggagttgctgttgccg. For analysis, all Clock genes were normalized to Gapdh for forebrain.

Statistics. All data are presented as mean \pm SEM. The effects of RF and genotype on locomotory behavior was analyzed by 2-way ANOVA with repeated measures, followed by post hoc analysis using Tukey's test when statistical significance between groups was evident. Differences in wheel running behavior were calculated as either the average wheel turns per 6 min bins for a given block of time or the average of wheel running ( $6 \mathrm{~min}$ bins) for $3 \mathrm{~h}$ before food presentation expressed as a percentage of total 
24 wheel running activity. During phase advancement of the light cycle, average ratios of wheel running for each hour during phase advance in the light cycle to average wheel running performed during that time in the previous light cycle was determined. Significant differences were determined using a one-way ANOVA followed by post hoc analysis (Tukey's test). For gene expression, ZT values were averaged for each gene at each time point and comparisons between WT and $M c 3 r-/$ - were analyzed using Student's $t$ test followed by Bonferroni's correction. For sleep state analysis, a two-way ANOVA was used comparing the effects of time with feeding state.

\section{Results}

$\mathrm{Mc} 3 \mathrm{r}$ are required for entrainment of anticipatory activity to

\section{restricted feeding}

Rodents subjected to periodic caloric availability under circadian (24 h) schedules exhibit entrainment of locomotory behavior and wakefulness anticipating meal time (Mistlberger, 1994; Gooley et al., 2006). Food anticipatory activity (FAA) was assessed in male B6 wild-type (WT) and $M c 3 r-/-$ mice using running wheels and spontaneous locomotory activity (SLA, movements in $x$ - and $z$-axis). For all studies, a $12 \mathrm{~h}$ light/dark cycle was set with lights-on at $0600 \mathrm{~h}$ (corresponding to ZT0); lights-off occurred at $1800 \mathrm{~h}$ (ZT12). A RF protocol was used where mice received a single meal equal to $50 \%$ of normal AL intake at $1300 \mathrm{~h}$ (ZT7). For studies using wheel cages, mice were weighed daily and the amount of food provided increased in $0.5 \mathrm{~g}$ increments to prevent severe $(>10 \%)$ weight loss. This was necessary for 4 of 20 WT (between day 5 and day 9 of RF), and 3 of $20 \mathrm{Mc} 3 \mathrm{r}-\mathrm{/}-$ mice (one on day 3 , and two on day 11 and day 12 , respectively).

WT $(n=18)$ and $M c 3 r-/-(n=20)$ mice aged $10-12$ weeks matched for body weight $(\mathrm{BW}, 26.0 \pm 0.3 \mathrm{~g}$ vs $27.3 \pm 0.8 \mathrm{~g}$, respectively) were acclimated to housing in wheel cages for 3 weeks. Wheel running activity during ad libitum feeding was not significantly different in $M c 3 r-/-$ mice compared with controls (Fig. $1 A, B$ ) (turns/d for WT, $8884 \pm 685$; for $M c 3 r-/-$ mice, $7159 \pm 634 ; p=0.075)$. RF was associated with robust FAA in WT, with $M c 3 r-/-$ mice exhibiting a significantly attenuated response (Fig. $1 A-C$ ). FAA accounted for $\sim 30 \%$ of total $24 \mathrm{~h}$ activity of WT, while for $M c 3 r-/-$ mice wheel running during anticipation accounted for $\sim 10 \%$ of total $24 \mathrm{~h}$ activity (Fig. $1 C$ ). With management of food intake to prevent excess weight loss, there was no significant difference in weight loss between genotypes (Fig. 1D).

Mice used to assess the effects of RF on SLA were also matched for BW (WT, $26.3 \pm 1.0 \mathrm{~g}$; $M c 3 r-/-, 25.3 \pm 1.3 \mathrm{~g} ; n=8$ /group). The $24 \mathrm{~h}$ profile of SLA was similar under ad libitum conditions (Fig. 2A, top) (data not shown). During RF, WT exhibited an increase in $x$ - and $z$-movements lasting $\sim 1$ h that was centered around food presentation (Fig. 2A) (data not shown). This re-
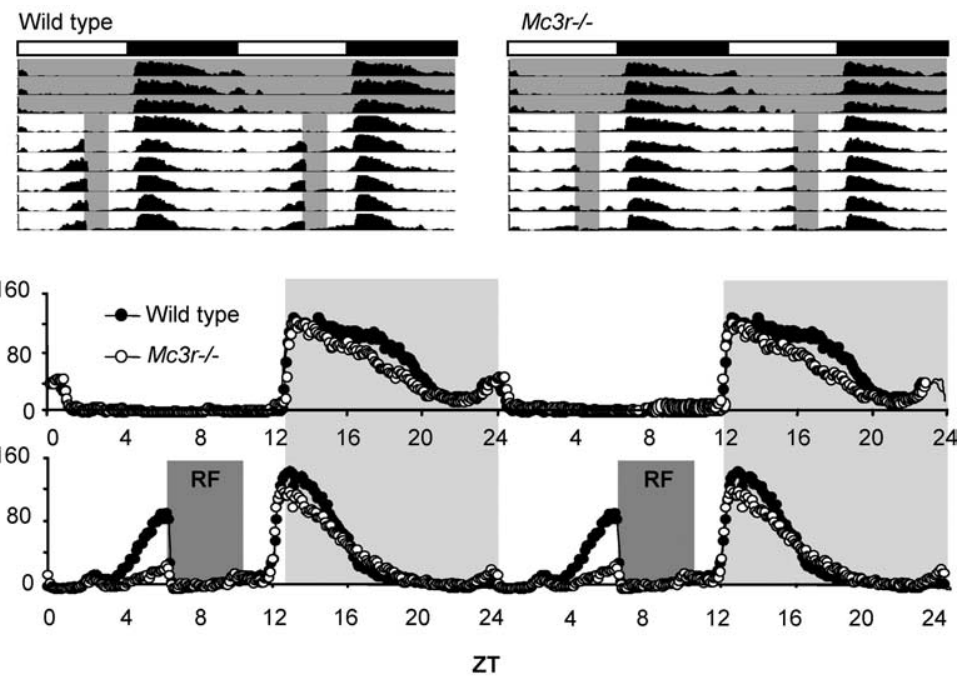

Days of RF

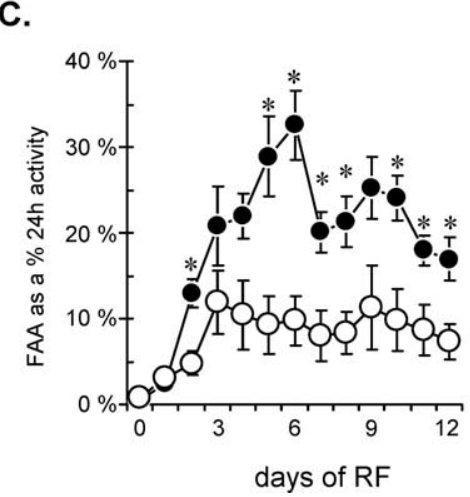

D.

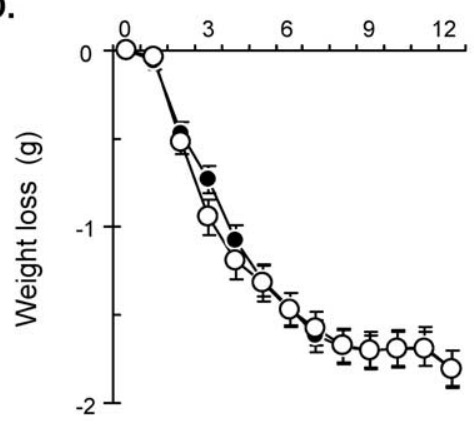

Figure 1. FAA in $M c 3 r-1-$ mice is significantly attenuated compared with WT mice. $A$, Averaged wheel running actograms for WT (left) and $M c 3 r-/-$ (right) mice subjected to $4 \mathrm{~h}$ of RF. Periods during which food was available are shaded. $\boldsymbol{B}$, Double 列 observed on day $2(p<0.05)$, day 4 , day 6 (both $p<0.01)$, and day $9(p<0.05)$. D. FAA adjusted for 24 h total activity. $(p<0.05)$. $\boldsymbol{E}$, Weight loss during RF was minimized to $\sim 10 \%$ of pre-RF weight. Black bar represents wheel turn responses during RF after weight stabilization.

sponse was not observed in $M c 3 r-1-$ mice. Analysis of $x$ - or $z$-axis movements spanning a time period $30 \mathrm{~min}$ prior and 30 min post food presentation and adjusted for $24 \mathrm{~h}$ activity (Fig. $2 B, C)$ indicated significant effects of days of RF $(p<0.001)$, genotype $(p<0.05)$, and a significant interaction between the effects of RF and genotype $(p<0.01)$. Total $24 \mathrm{~h}$ activity for movement in the $x$-axis was significantly affected by RF $(p<$ $0.001)$, with no effect of genotype $(p=0.222)$. For $24 \mathrm{~h}$ movements in the $z$-axis, there was no significant effect of RF or genotype (Fig. $2 E$ ) (effect of genotype, $p=0.641$; effect of RF, $p=0.094$ ).

Effects of Mc3r deficiency on energy metabolism during RF Baseline daily food intake of WT and $M c 3 r-/-$ mice housed in metabolic chambers using to monitor SLA was not significantly different (Fig. 3A). However, there was a subtle difference in the daily pattern of intake with $M c 3 r-/-$ mice exhibiting reduced intake during the dark period (Fig. 3B). This was associated with a significant reduction in the amplitude (peak minus nadir, calculated by subtracting intake during lights-on from the dark period). During RF, mice were presented with $2.5 \mathrm{~g}$ of food equivalent to $40 \mathrm{~kJ}$, representing a $30 \%$ reduction relative to ad libitum intake (Fig. $3 B$ ), which visual inspection indicated was mostly 
A

- WT

Mc3r-/-
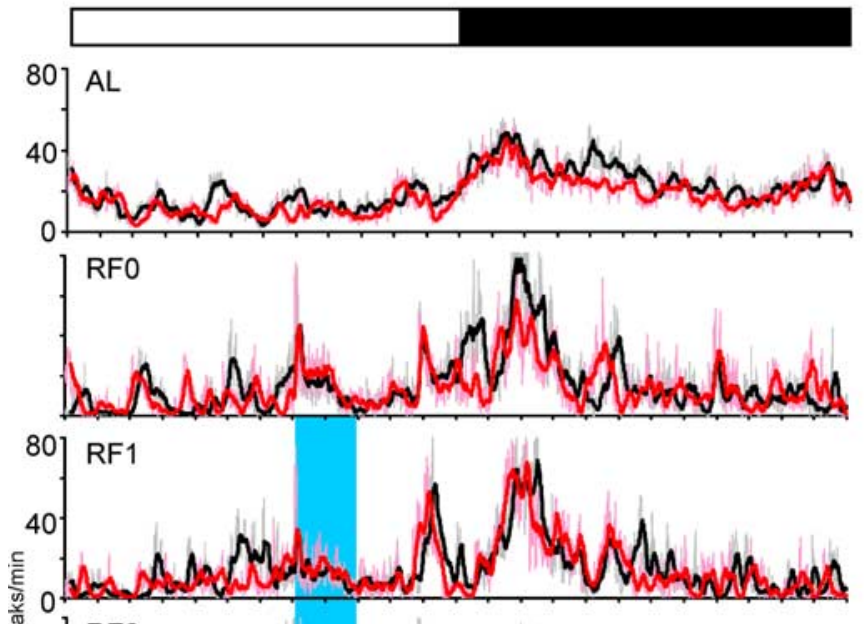

离

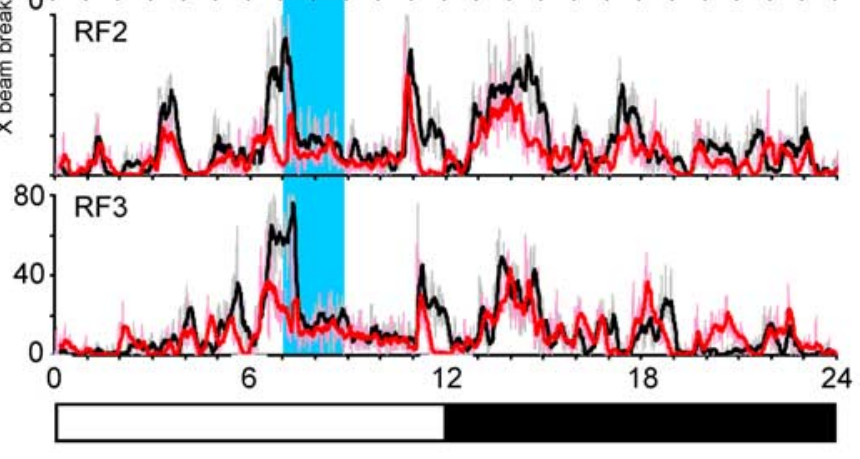

B

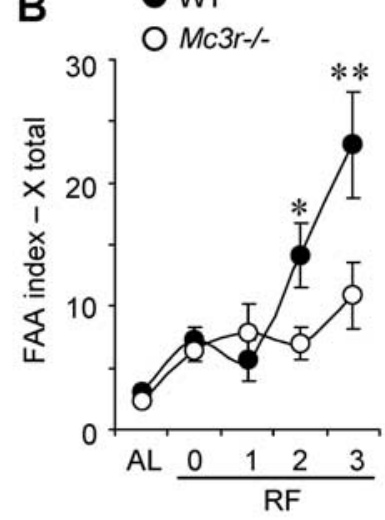

C

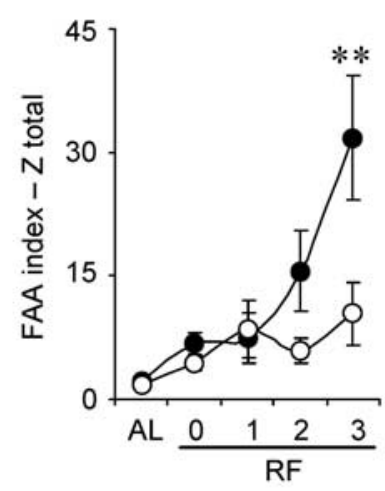

D

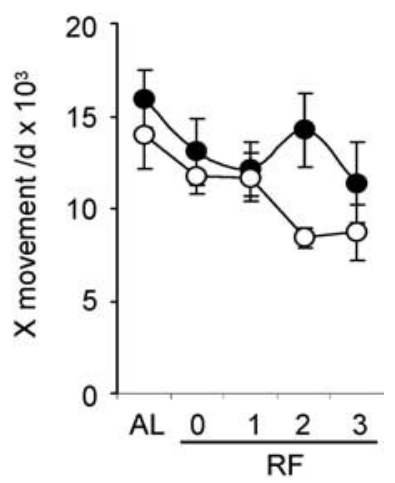

E

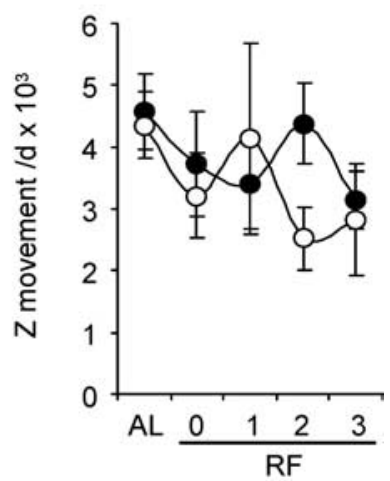

Figure 2. Effect of RF on home cage activity of Mc $3 r-/$ - mice and WT mice. A, WT and Mc $3 r-$ - - littermates, matched for weight and adiposity, were placed into a CLAMS system and home cage physical activity was monitored in 1 min bins/24h using infrared beam breaks. $\boldsymbol{B}$, Averaged $x$-axis movements from WT and $M c 3 r-/-$ mice showing the increased FAA (FAA index, movements over a $1 \mathrm{~h}$ period centered around food presentation) during RF that is dependent on $\mathrm{Mc} 3 \mathrm{r}$. $C$, Averaged $z$-axis movements from WT and $M c 3 r-/-$ mice showing the increased FAA index during RF that is dependent on Mc3r. The effects of RF and genotype on FAA index in $x$ - and $z$-movements were significant as assessed by tw0-way ANOVA (for RF, $p<0.01$; for genotype, ${ }^{*} p<0.05$, ${ }^{* *} p<$ 0.01). Total $24 \mathrm{~h}$ movements in the $x$ - $(\boldsymbol{D})$ and $z-(\boldsymbol{E})$ axes were not significantly different in WT and $M c 3 r-/-$ mice. $n=8 /$ group.

consumed within $4 \mathrm{~h}$ of presentation. Consistent with reduced energy consumption, RF was associated with a $30-35 \%$ reduction in $24 \mathrm{~h}$ EE regardless of genotype (Fig. 3C, top). Food presentation during RF was associated with a marked and rapid increase in EE, representing the thermic effect of food (TEF) (Fig. $3 D-G)$. TEF was normal in $M c 3 r-/-$ mice relative to controls, suggesting the consumption and oxidation of equivalent amounts of energy. Moreover, weight loss during RF was also not significantly different between the two groups (weight loss in $\mathrm{g}$ for WT, $3.1 \pm 0.4$; for $M c 3 r-/-, 3.6 \pm 0.5, p=0.45$; and as a percentage of starting weight for WT, $11.5 \pm 1.1$; for $M c 3 r-/-$, $13.6 \pm 1.6, p=0.287)$.

The RER is an indicator of the proportion of energy derived from carbohydrate or fatty acids, and after removal of food (RF0) RER rapidly declined to a value of 0.7 consistent with mobilization and oxidation of fat reserves (Elia and Livesey, 1988). Food presentation was associated with a rapid increase in RER, coinciding with oxidation of a diet with a high carbohydrate and low fat content. Again, the initial effect of food presentation was not markedly affected by genotype. However, by the third day of RF a significant difference in $24 \mathrm{~h}$ RER was observed (Fig. 3C, bottom; Fig. $3 H$ ). Assessment of hourly data indicated that the initial rise in RER on the third day of RF associated with feeding was normal for $M c 3 r-/-$ mice. The difference in RER between genotype was primarily observed $4-5 \mathrm{~h}$ after food presentation (Fig. $3 H$ ), associated with a significant difference in the area under the curve $(p<0.01)$.

Collectively, the analysis of energy metabolism suggest that food presented to $M c 3 r-/-$ and WT mice is rapidly consumed and oxidized, with no significant differences between groups. However, there are significant differences in substrate preference for oxidation. During periods of RF, $M c 3 r-/-$ mice may be less efficient at using carbohydrate to generate energy.

Increased wakefulness anticipating RF time is not observed in Mc3r-/- mice

EEG and EMG electrodes were implanted into WT $(n=9)$ and $M c 3 r-/-(n=6)$ mice. Twenty-four hour patterns of wakefulness in a light/dark setting were initially assessed under conditions of ad libitum feeding and then after $4 \mathrm{~d}$ of RF (Fig. 4). In WT mice, an increase in wakefulness was observed during the $2 \mathrm{~h}$ before food presentation and a marked reduction in wakefulness late in the lights-off phase (Fig. $4 A$ ). In contrast, $M c 3 r-/-$ mice only exhibited a brief period of increased wakefulness that coincided with presentation of food at ZT7 (Fig. 4B).

Collectively, the results from the experiments assessing FAA using wheel cages, home cage activity and wakefulness all indicate 
that $\mathrm{Mc} 3 \mathrm{r}$ are required for the coordinated development of anticipatory activity and arousal associated with restricted feeding.

Genetically obese mice matched with Mc3r-/- mice for adiposity have FAA While matched for BW, Mc3r-/- mice before RF exhibited a modest increase in adiposity (percentage body fat) when compared with WT (15.4 $\pm 1.5 \%$ compared with $8.3 \pm$ $0.5 \%, p<0.01)$. To determine whether the attenuation of FAA in $\mathrm{Mc} 3 \mathrm{r}-1-$ mice was specifically due to loss of receptor function or obesity, we examined FAA in $M c 4 r-/-$ $(n=4)$ and $\operatorname{KKAy}(n=10)$ mice. These mice were matched with an independent cohort of $M c 3 r-/-$ mice $(n=10)$ for adiposity, and subject to RF for 2 weeks. Lean male WT controls were included in the study $(n=10)$.

$M c 3 r-1-$ mice again exhibited an attenuated FAA, with Mc4r-/- and KKAy exhibiting FAA statistically indistinguishable from WT mice after $12 \mathrm{~d}$ of RF (data not shown). These results indicate that the impaired FAA observed in $\mathrm{Mc} 3 \mathrm{r}-\mathrm{I}-$ mice is not due to increased adiposity.

\section{Response of $\mathrm{Mc3r}-/-$ mice to phase advance in light}

Another aspect of the behavioral phenotype associated with loss of Npas2 is an exaggerated locomotory response to phase advances in the light/dark cycle (Dudley et al., 2003). To investigate whether impaired entrainment to feeding in $M c 3 r-1-$ mice would be associated with increased dependency on light cues, the mice used to investigate FAA in wheel cage were subjected to a $5 \mathrm{~h}$ phase advance in the light/dark cycle. Lights were switched off between ZT7 and ZT19. The presence of light potently inhibited activity in WT and $M c 3 r-/-$ mice (Fig. 5A, compared $\mathrm{d} 0$ and $\mathrm{d} 1$ ). Both strains exhibited a gradual advance (transients) in the onset of activity toward ZT7. However, for $M c 3 r-1-$ mice the advance was more robust, with the transition occurring more rapidly and retaining the clear early peak in activity observed before the phase shift in light setting (Fig. 4A). When expressed as a ratio of total peak activity before phase shift, Mc3r-/- mice exhibited a significantly increased initiation of activity $1 \mathrm{~h}$ ahead of WT littermates during the phase advance (Fig. 5B). $M c 3 r-1-$ mice are thus similar to Npas2-1mice in exhibiting impaired entrainment to feeding time and increased dependency on light cues governing circadian rhythms (Dudley et al., 2003).

\section{Arrhythmic expression of clock genes in the forebrain of} Mc3r-/- mice during restricted feeding Canonical clock oscillators involve a positive limb, comprised of the basic helix-loop-helix transcription factors circadian loco-
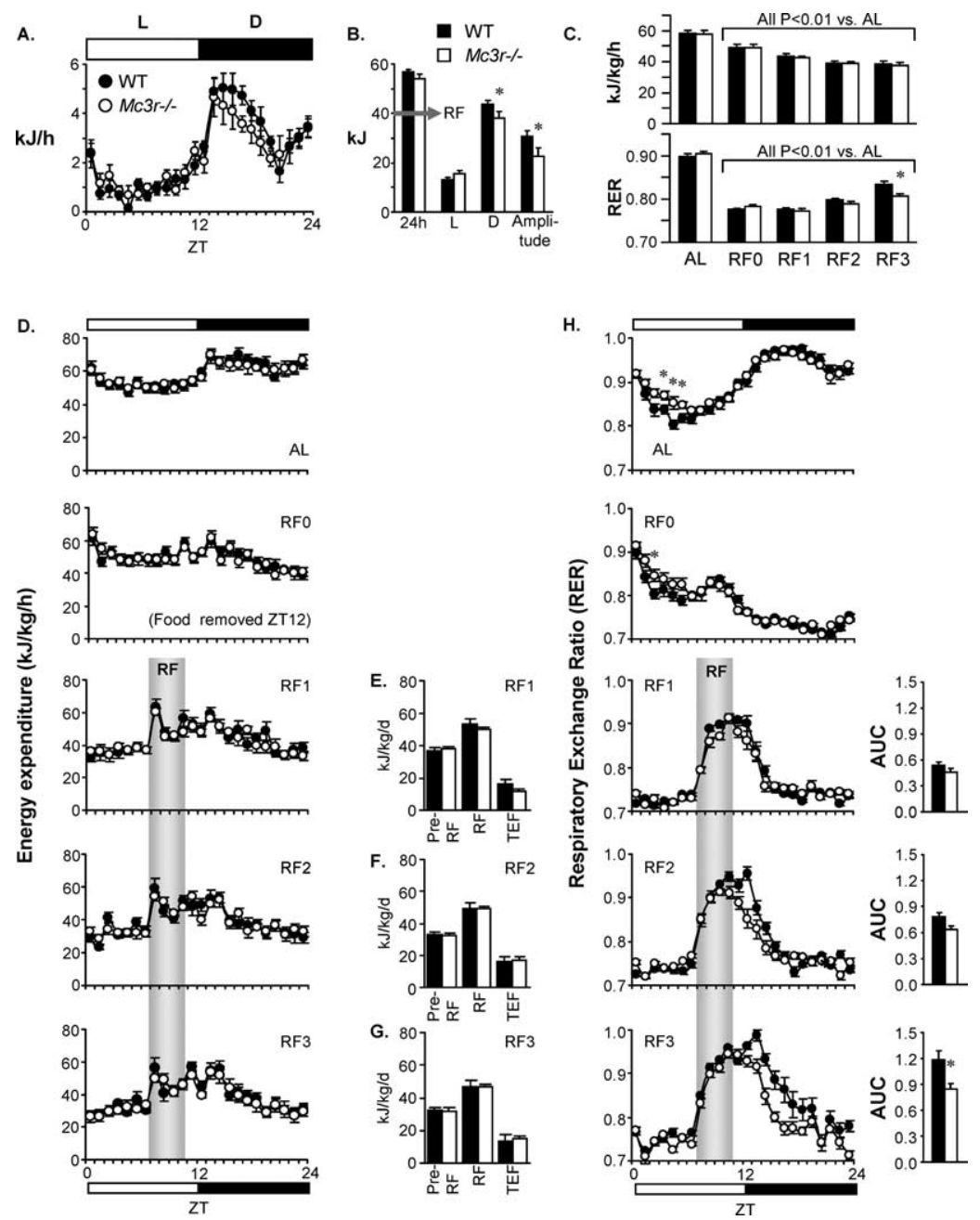

Figure 3. Effect of RF on energy metabolism in WT and Mc $3 \mathrm{r}-/-$ mice. A, Baseline hourly food intake data for AL fed WT and Mc3r-1 - mice. $\boldsymbol{B}$, Breakdown of baseline food intake data into total $24 \mathrm{~h}$ intake, intake during lights-on (L) and dark (D) periods, and amplitude (intake during dark-light). The data are the mean of $3 \mathrm{~d}$ of recordings. While $24 \mathrm{~h}$ intake was not significantly different, $M c 3 r-1-$ mice exhibited an altered $24 \mathrm{~h}$ pattern of intake suggesting reduced intake during the dark period. The gray arrow represents the amount of energy provided in the diet ( $40 \mathrm{~kJ}$, or a reduction of $\sim 30 \%$ compared with ad libitum intake) during RF. ${ }^{*} p<0.05$. C, Effect of $3 \mathrm{~d}$ of RF (RF0 -3 ) of $24 \mathrm{~h}$ EE and RER. RF was associated with a compensatory $35 \%$ reduction in $\mathrm{EE}(p<0.01$ vs ad libitum fed mice) which was not significantly affected by genotype. Twenty-four hour RER was reduced by RF $(p<0.001)$ indicating mobilization and oxidation of fat reserves; however, there was a tendency $(p=0.063)$ for an effect of genotype. Post hoc analysis indicates a significant difference in $24 \mathrm{~h}$ RER by the third day of RF. ${ }^{*} p<0.01$. D, Hourly EE data showing baseline and RF periods. Note that the removal of food on RFO prevented the normal rise in EE in the dark period. Food presentation was associated with a rapid and equivalent increase in $\mathrm{EE}$, the TEF, in WT and $M c 3 r-/-$ mice. $E-G$, Averaged EE in the $4 \mathrm{~h}$ period preceding RF (Pre-RF, also an indicator of basal metabolic rate during fasting), EE during the $4 \mathrm{~h}$ period after food presentation (RF), and TEF calculated by subtracting Pre-RF from RF. Note that EE and TEF of $M c 3 r-/$ - mice was normal during RF. $\boldsymbol{H}$, Altered substrate metabolism in $M c 3 r-1-$ mice during RF. Data shown represent hourly measurements during baseline (AL) and RF. During AL, Mc3r- / - mice exhibited an elevated RER in the early lights-on period perhaps related to the altered daily pattern of food intake $\left({ }^{*} p<0.05\right)$. Withdrawal of food led to a reduction in the RER close to 0.7 , indicating oxidation of fat reserves. RER rapidly increased with food presentation, consistent with oxidation of a low fat/high carbohydrate diet. By RF3, the initial peak in RER during RF was similar in WT and Mc3r - I - mice. However, the duration of the peak was reduced in Mc $3 \mathrm{r}-1-$ mice compared with controls. The area under the curve for the increase in RER (AUC) was calculated using the pre-RF period as baseline, and demonstrated a significant $\left({ }^{*} p<0.01\right)$ reduction on RF3. Collectively, these data suggest that, on the third day of $\mathrm{RF}$, consumption and oxidation of energy in Mc3r- - - and WT mice was similar; however, Mc3r- / - mice exhibited an abnormal preference for fat and carbohydrate oxidation in the postprandial phase. 
A. WT

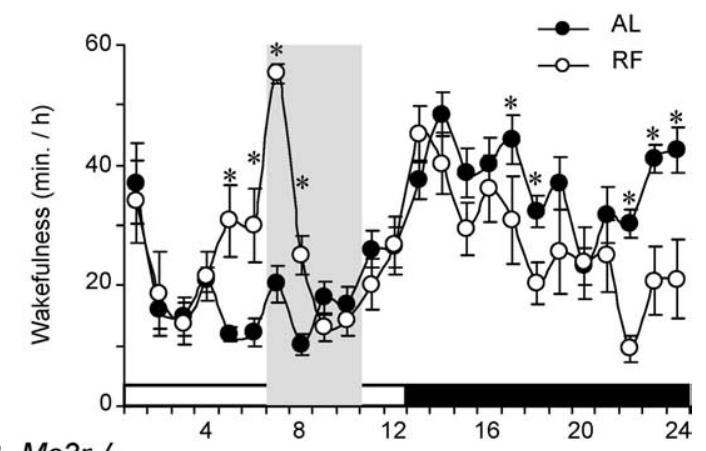

B. $M c 3 r-/-$

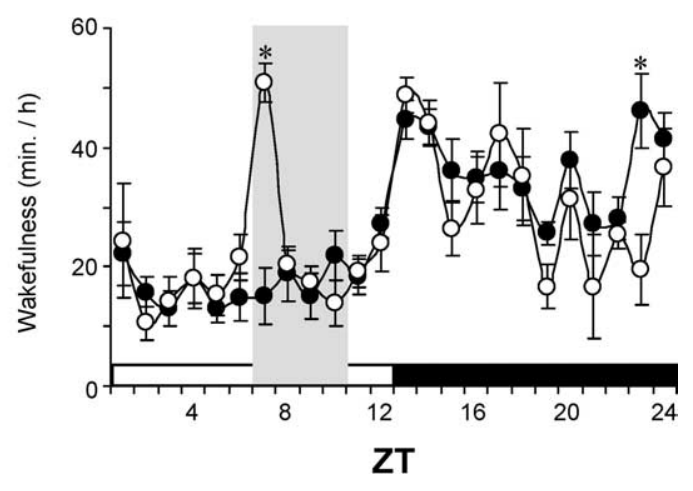

Figure 4. Entrainment of anticipatory increase in wakefulness to RF in WT but not $M c 3 r-1-$ mice. Twenty-four hour patterns of wakefulness are shown for WT $(\boldsymbol{A}, n=9)$ and $M c 3 r-1-(B, n=6)$ mice during AL (solid circles in both panels) or after $3 \mathrm{~d}$ of restricted feeding (open circles). RF was associated with increased wakefulness in WT mice in the $2 \mathrm{~h}$ period preceding food presentation and reduced wakefulness in the lights-off phase. In the lights-on phase, $M c 3 r-1-$ mice exhibited increased wakefulness restricted to the $1 \mathrm{~h}$ after food presentation. ${ }^{*} p<0.05$ AL vs RF.

heterodimers, and comprise the negative limb. Npas 2 is required for normal regulation of Per2 expression in cultured cells and forebrain (Reick et al., 2001; Dudley et al., 2003). The pattern of oscillation of Npas 2 and Per2 mRNA expression in the forebrain is regulated by feeding time (Dudley et al., 2003). This association may be critical for FAA, as homozygous null Per2 and Npas 2 mice both deficits in FAA (Dudley et al., 2003; Feillet et al., 2006). As loss of Npas2, Per2 and Mc3r functions have similar effects on behavioral adaptation to feeding time, we hypothesized that Mc3r are critical for normal regulation of clock activity in the brain.

Cortical expression of circadian oscillator genes was analyzed 10-12 week male $M c 3 r-/-$ and WT controls under conditions of ad libitum feeding or RF. The results are shown in Figure 6, with data from ad libitum fed mice provided in panels on the left, and mice subject to RF on the right. Marked differences in cortical Bmal1, Npas2 and Per 2 expression were observed in $M c 3 r-/-$ mice compared with controls under ad libitum feeding conditions (Fig. 6A-C, left panels). In particular, cortical Bmal1 mRNA expression was tenfold lower in $M c 3 r-/-$ mice during the peak expression in WT mice at $0600 \mathrm{~h}$. RF was also associated with marked differences in amplitude of the circadian profile of all three genes in the cortex of $M c 3 r-/-$ mice relative to controls (Fig. 6A-C, right panels). These observations demonstrate that $\mathrm{Mc} 3 \mathrm{r}$ are required for normal patterns of clock activity in the cortex.
Regulation of clock gene expression in the forebrain by infusion of melanocortin receptor antagonists

To determine whether inhibition of Mc3r acutely affects clock activity, we examined the $24 \mathrm{~h}$ profile of clock genes in mice administered with AgRP ${ }^{82-131}$ or ACSF through cannula's targeting the lateral ventricle. Mice subject to RF were in a negative energy balance, and lost weight during the treatment period. However, AgRP infused mice adapted poorly to RF, consuming less food (Fig. 7A) and losing more weight during the first week of infusion (Fig. $7 B$ ). For the groups fed in the dark phase, mice were provided $4.7 \mathrm{~g}$ of food at the onset of the dark phase. As expected, there was a tendency ( $p=0.06)$ for AgRP-infused mice fed during the dark period to gain more weight (Fig. $6 B$ ). While food intake data for the dark phase fed animals was not recorded, visual examination indicated that after $2-3 \mathrm{~d}$ mice were eating most of the food provided.

Mice infused with $\mathrm{AgRP}^{82-131}$ exhibited abnormal cortical clock gene expression (Fig. 7C-E, right and left panels). Bmalland Npas2 expression was abnormal under both ad libitum and RF conditions. Per2 expression was similar between ACSF and AgRP during nocturnal pair feeding; however during RF feeding AgRP ${ }^{82-131}$ infusion was associated with asynchronous rhythms (Fig. 6E, compare right and left panels). These results demonstrate that central infusion of a melanocortin receptor antagonist disrupts normal regulation of clock genes in the forebrain.

\section{Discussion}

When food is freely available, periods of wakefulness are associated with peak ingestive behavior. However, the entrainment of rhythms in behavior anticipating nutrient availability confers a selective advantage in nutrient poor environments. Entrainment to light and calories involves a complex regulation of clock systems distributed throughout the CNS and periphery. The master pacemaker clock residing in the SCN is a light entrainable oscillator. The location and characterization of the "master" food entrainable oscillator (FEO) is controversial. The DMH may be involved in maintaining entrainment to feeding time (Gooley et al., 2006; Mieda et al., 2006; Fuller et al., 2008). Dense Mc3r expression has been reported in this area (Roselli-Rehfuss et al., 1993), and the similarities in the behavioral phenotype associated with lesions in the $\mathrm{DMH}$ and $\mathrm{Mc} 3 \mathrm{r}$ signaling are highly suggestive. However, other studies have demonstrated retention of food entrainment in DMH-lesioned animals (Landry et al., 2006, 2007). Nevertheless, our results are significant in demonstrating the involvement of the hypothalamic melanocortin system acting through $\mathrm{Mc} 3 \mathrm{r}$ in the expression of adaptive entrainment of behavior in response to feeding cues. While melanocortin neurons located in the NTS regulate ingestive behavior (Cone, 2005, 2006), the highest density of Mc3r mRNA was observed in the hypothalamus, with no expression observed in the brainstem (Roselli-Rehfuss et al., 1993).

Systems governing circadian rhythms are important for an organism's ability to predict daily recurrent events. Our findings suggest that $\mathrm{Mc} 3 \mathrm{r}$ containing neurons regulate inputs maintaining proper cyclic oscillation of core circadian oscillator genes in the forebrain. Mc3r deficiency results in impaired synchronization of clock genes in the forebrain during AL feeding, as well as impaired adaptive behavioral responses associated with RF. Central infusion of AgRP, which acts as an antagonist at the Mc3r, also affects clock activity in the forebrain. Indeed, AgRP-infused mice adapted poorly to daytime feeding. Mice infused with AgRP fed during the dark period gained more weight, consistent with 
the anabolic actions of this neuropeptide. However, AgRP-infused mice fed during the daytime fared worse than ACSFinfused controls, requiring $7 \mathrm{~d}$ of RF before ingesting the full amount of food available and losing more weight.

We assessed entrainment of wakefulness to periodic nutrient availability, demonstrating a clear distinction in wakefulness between WT and $M c 3 r-1-$ mice during the period preceding food presentation. This period corresponds with data showing anticipatory wheel running behavior in WT mice subject to RF. The observations presented here also suggest that Mc3r plays a role in the homeostatic drive regulating clocks residing outside the SCN. Precedence between the function of clock systems and rhythms of arousal has been established in previous studies (Laposky et al., 2005), where impaired levels of sleep state and wakefulness were reported in mice with mutated Bmall/Mop3 gene expression. Loss of the Clock homolog, Npas2, and of the clock output gene Per2 also results in delayed expression or loss of FAA, respectively (Dudley et al., 2003; Feillet et al., 2006). Mc3r-/mice have reduced synchronization of both Npas2 and Per2 in the forebrain during RF. Alterations in oscillation of both or either of genes could play a role in the impaired entrainment of $M c 3 r-/-$ mice to RF.

The FEO system has been suggested not to reside in a single area, but represent a system that is distributed throughout the brain and periphery (Stephan, 2002). $\mathrm{Mc} 3 \mathrm{r}$ appear to regulate many aspects of ingestive behavior, arousal, and metabolism, likely through actions that are distributed throughout the brain. Indeed, melanocortin neurons dispersed throughout the forebrain and brainstem affect many aspects of energy homeostasis (Cone, 2005). Hypothalamic melanocortin neurons are also logical candidates for transmitting feeding-related inputs into neurons governing the development of anticipatory behaviors. These neurons form a distributed neural network in the brain that responds to humoral indicators of meal consumption, such as ghrelin, insulin, and cholecystokinin (Cone, 2005). Studies using scheduled feeding protocols have demonstrated that Pomc neurons respond rapidly to meals (Johnstone et al., 2006; Singru et al., 2007). AgRP neurons also receive inputs from orexin neurons in the lateral hypothalamus, providing further connectivity with arousal and sleep state (van den Top et al., 2004). Pomc and AgRP neurons innervate hypothalamic areas involved in entrainment of anticipatory behaviors to feeding (Bagnol et al., 1999; Haskell-Luevano et al., 1999; Singru et al., 2007). The dorsomedial part of the VMH and the ventral tegmental area, implicated in anticipatory and reward-seeking behaviors (Choi et al., 1998;
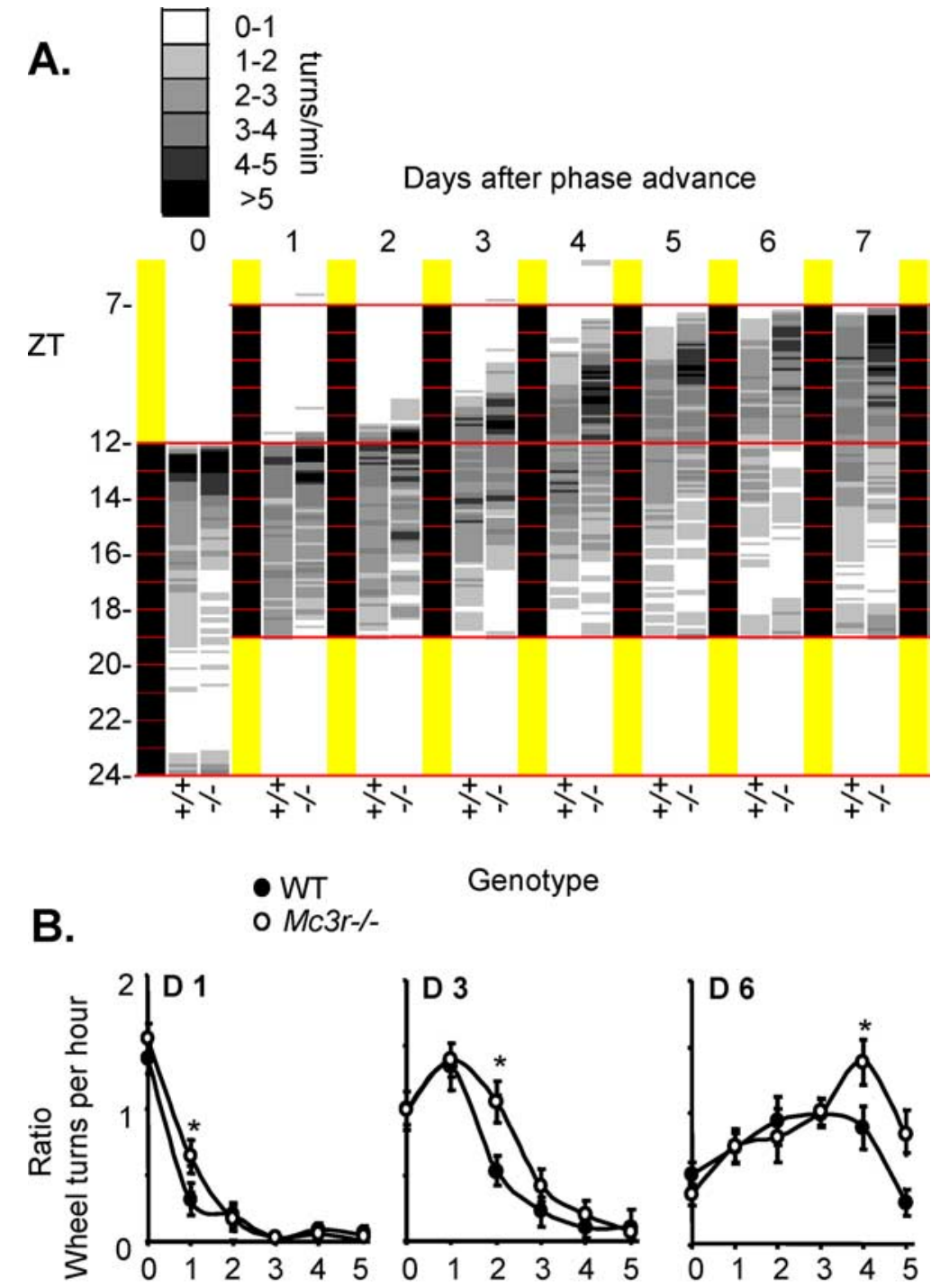

Phase advance (hour)

Figure 5. Effect of a $5 \mathrm{~h}$ phase advance on activity initiation in $\mathrm{Mc} 3 \mathrm{r}-\mathrm{I}-$ mice and WT mice. WT and $M c 3 r-/-$ littermates were placed into wheel running cages and physical activity was monitored in 6 min bins $/ 24 \mathrm{~h}$. $\boldsymbol{A}$, Averaged wheel running actograms from WT and $\mathrm{Mc} 3 \mathrm{r}-\mathrm{I}-$ mice showing baseline activity and response to a $5 \mathrm{~h}$ phase advance. The yellow and black sections indicate the lights-on and lights-off periods, respectively. Mean wheel running activity is shown for WT $(+/+, n=18)$ and $\mathrm{Mc} 3 \mathrm{r}$-deficient $(-/-, n=20)$ mice using a gray scale, with white representing no or minimal activity, and black representing peaks in activity. $\boldsymbol{B}$, Averaged ratio of wheel running activity for each hour of the phase advance adjusted for normal activity (average normal wheel running for the $5 \mathrm{~h}$ after lights off) over the three experimental days. Onset of wheel running was dependent on genotype and was statically significant $\left(^{*}\right)$ between $\mathrm{Mc} 3 \mathrm{r}-1-$ compared with WT mice, on hour 1 of day 1 ( $p<$ $0.05)$, on hour 2 on day $3\left({ }^{*} p<0.05\right)$, and on hour 4 on day $6(p<0.02) . n=18-20$ per group. One-way ANOVA with Tukey's post hoc test was performed to detect significant differences in wheel running data.

Gooley et al., 2006), exhibit dense Mc3r mRNA expression (Roselli-Rehfuss et al., 1993).

In peripheral tissues, clocks respond to local and humoral inputs of energy status (Rutter et al., 2002; Stephan, 2002; Kornmann et al., 2007). Whether Mc3r are involved in specifically entraining behavior to meal time, or are also required for entrainment of peripheral clocks regulating metabolism, requires further investigation. In the current study, we observed no difference in daily EE of $M c 3 r-/-$ mice during conditions of ad libitum or restricted feeding, while the profile of the TEF associated with food presentation was also normal. The observation of normal EE in $\mathrm{Mc} 3 \mathrm{r}-\mathrm{/}-$ mice regardless of caloric intake agrees 


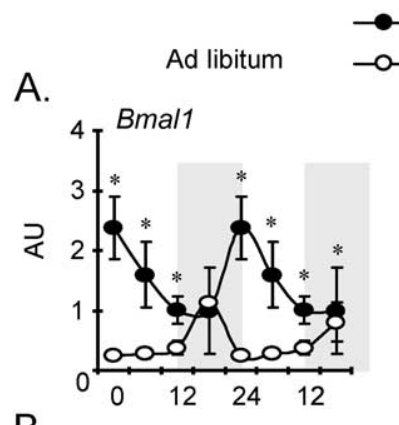

B.

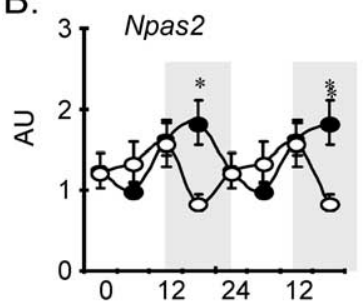

C.

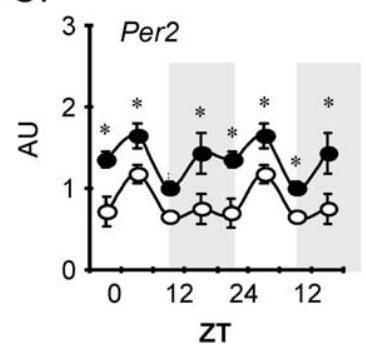

RF
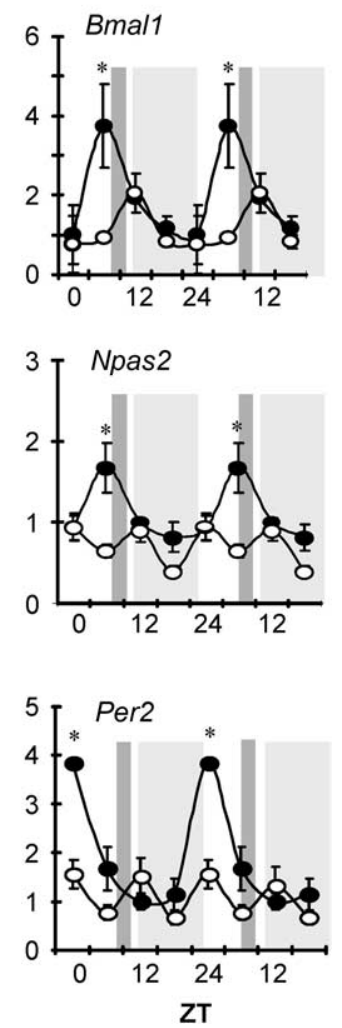

Figure 6. Core circadian oscillator gene expression is asynchronous in $\mathrm{Mc} 3 \mathrm{r}-\mathrm{I}-$ mice compared with WT mice. Double plotted gene expression data for $(\boldsymbol{A}) \operatorname{Arntl} / \mathrm{Bmal} 1(\boldsymbol{B}) \mathrm{Naps} 2$ and $(\boldsymbol{C}$ Per2 under AL (left panels, gray squares represents lights off) or RF conditions (right panels, feeding time is indicated by a dark gray rectangle). Lights off phase is indicated by a light gray shade. Significant differences $\left(^{*}\right)$ in gene expression were observed between $\mathrm{Mc} 3 \mathrm{r}-\mathrm{I}-$ mice compared with WT at each time point ( $p<0.05)$ ( $n=4-5$ per group).

with previous studies using indirect calorimetry to assess metabolism and diet-induced thermogenesis (Butler et al., 2000; Chen et al., 2000; Butler, 2006; Sutton et al., 2006). There was however evidence of abnormal substrate metabolism in $M c 3 r-/-$ mice during RF. This was not observed immediately before or after food presentation, but was most noticeable $4-5 \mathrm{~h}$ after food presentation. Altered nutrient partitioning is a significant factor contributing to the obese phenotype of Mc3r deficient mice (Butler, 2006); the results of this study indicate a failure to regulate fatty acid and carbohydrate metabolism during periods of intermittent nutrient availability. Studies investigating entrainment and metabolic adaptation in the peripheral tissues of $\mathrm{Mc} 3 \mathrm{r}-\mathrm{I}-$ mice to RF are clearly warranted.

The observation that the absence of FAA in $M c 3 r-1-$ mice housed in metabolic chambers is not associated with altered EE was surprising. However, it is possible that a comparably minor increase in ambulation in a small chamber may have a minor impact on EE. Indeed, while $M c 3 r-/-$ mice exhibit reduced physical activity in the home cage, this has not been associated with measurable reduction in daily EE. Physical activity in relatively inactive conditions represents a minor (10\%) component of the total daily energy budget, thus minor changes in ambulation may therefore be insufficient to markedly change total EE. This may not be the case for mice housed in wheel cages, where activity-based EE would be far greater. However, it is important to note that the amount of food available was manipulated in

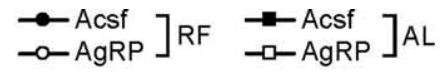

A. Food intake

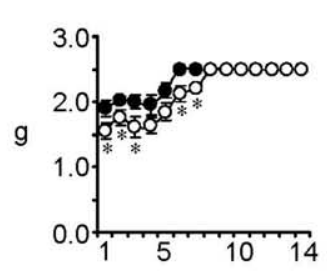

Days of treatment

Ad libitum

C. Bmal1

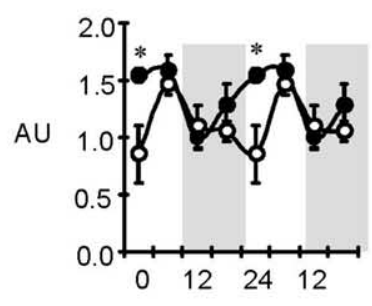

B. Change in body weight

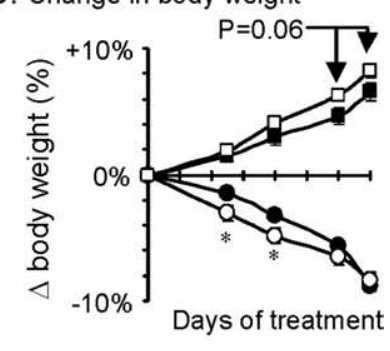

RF

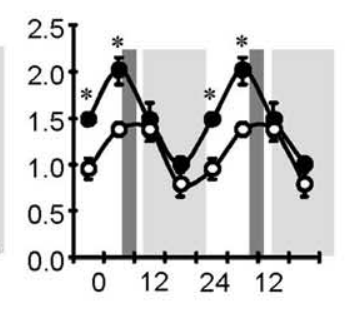

D. Npas2

$\mathrm{AU}$
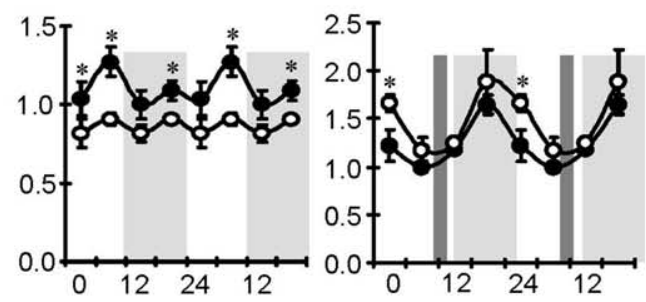

E. Per2

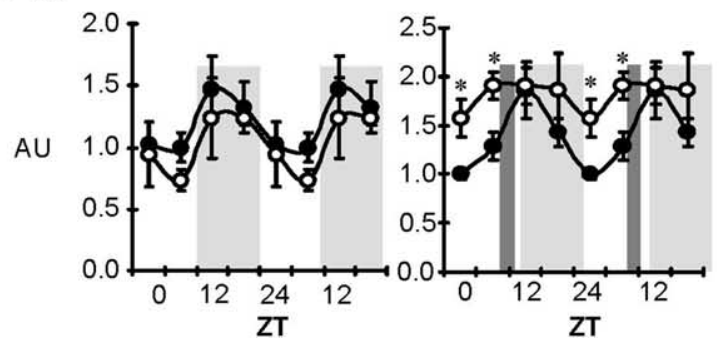

Figure 7. Chronic infusion of AgRP ${ }^{82-131}$ into the lateral ventricle is associated with impaired adaptation to RF. $A$, Food intake during RF for mice receiving $0.05 \mathrm{nmol} / \mathrm{d} \mathrm{AgRP}{ }^{82-131}$ or ACSF. $\boldsymbol{B}$, Percentage change in body weight of mice receiving AgRP ${ }^{82-131}$ or ACSF $(n=20$ / group). These treatment groups were further split into two subgroups subject to RF, or an AL group where mice receiving ACSF were fed the same amount of food with the AgRP ${ }^{82-131}$ treated mice at $1800 \mathrm{~h}$ ( $=$ ZT12). Note that mice treated with AgRP ${ }^{82-131}$ took longer adapt to $\mathrm{RF}$ and to consume the total amount of food available $(\boldsymbol{A})$, associated with significantly greater weight loss during $\operatorname{RF}(\boldsymbol{B}) .{ }^{*} p<0.05$ versus ACSF within mice subject to RF. $\boldsymbol{C}-\boldsymbol{E}$, Pattern in the rhythm of cortical expression of clock genes is altered in mice treated with AgRP ${ }^{82-131} \mathrm{com}$ pared with ACSF-treated controls under either ad libitum (left panels, $n=4$ per time point) or $\mathrm{RF}$ (right panels, $\mathrm{n}=5$ or 6 per time point RF) conditions. Mice were killed every $6 \mathrm{~h}$ and clock genes analyzed by RT-PCR. Gene expression over $24 \mathrm{~h}$ is double plotted. Gray shading represents dark phase and dark gray vertical shading denotes meal time for RF feeding protocol. ${ }^{*} p<0.05$ versus ACSF-treated.

mice housed in wheel cages subject to RF to prevent excess weight loss. In addition, while RF was associated with FAA in WT mice there was a compensatory reduction in activity during the dark period (Fig. $1 B$ ).

Neuronal populations outside of the SCN play a critical role in 
maintaining circadian rhythms of arousal and core body temperature under conditions of ad libitum feeding and during RF (Saper et al., 2005). Mc3r expressing neurons in the dorsomedial part of the VMH may be involved in integrating nutrient signals associated with $\mathrm{AL}$ or RF conditions, forming relays facilitating timing of arousal with metabolic requirements associated with food seeking behavior. Some but not all studies have demonstrated that lesions of the VMH result in loss of FAA, increased body weight, hyperphagia and hyperinsulinemia making it a potential site of a FEO (Choi et al., 1998). The VMH is thought to control ingestive behaviors, and the counter-regulatory responses to hypoglycemia (King, 2006). Compelling evidence also exists for a clock mechanism driving a FEO residing in the DMH. In a recent study where localization of chemical lesions was carefully analyzed, DMH lesions resulted in a loss of FAA whereas VMH lesions amplified FAA (Gooley et al., 2006). It was also recently demonstrated that the $\mathrm{DMH}$ is the only site within the brain that exhibits robust entrainment and maintenance of a clock-driven oscillator regulated by RF (Mieda et al., 2006). Neurons contained in both the $\mathrm{VMH}$ and $\mathrm{DMH}$ may thus regulate convergent and disparate aspects of food entrainment.

Extra-hypothalamic sites expressing Mc3r could also play a role in the regulation of anticipatory behaviors. $M c 3 r$ mRNA are expressed in the ventral tegmental area containing dopamine neurons projecting to cortical regions involved in reinforcement and decision making (Roselli-Rehfuss et al., 1993). Conditional restoration of $\mathrm{Mc} 3 \mathrm{r}$ in various areas of the hypothalamus may prove useful for identifying specific neuronal populations involved in entrainment.

\section{Conclusions}

Clocks integrate cues from the environment and systemic signals of energy status to regulate diverse cellular and physiological functions (Rutter et al., 2002; Kohsaka and Bass, 2007). As such, clocks may represent a conduit through which the melanocortin system coordinates multiple adaptive processes during periods of limited nutrient availability. These results imply that the melanocortin system, acting through $\mathrm{Mc} 3 \mathrm{r}$, is an integral component of the neural systems governing entrainment of rhythms in behavior during limited nutrient availability.

\section{References}

Bagnol D, Lu XY, Kaelin CB, Day HE, Ollmann M, Gantz I, Akil H, Barsh GS, Watson SJ (1999) Anatomy of an endogenous antagonist: relationship between Agouti- related protein and proopiomelanocortin in brain. J Neurosci 19:RC26.

Butler AA (2006) The melanocortin system and energy balance. Peptides 27:281-290

Butler AA, Kesterson RA, Khong K, Cullen MJ, Pelleymounter MA, Dekoning J, Baetscher M, Cone RD (2000) A unique metabolic syndrome causes obesity in the melanocortin-3 receptor-deficient mouse. Endocrinology 141:3518-3521.

Butler AA, Marks DL, Fan W, Kuhn CM, Bartolome M, Cone RD (2001) Melanocortin-4 receptor is required for acute homeostatic responses to increased dietary fat. Nat Neurosci 4:605-611.

Chen AS, Marsh DJ, Trumbauer ME, Frazier EG, Guan XM, Yu H, Rosenblum CI, Vongs A, Feng Y, Cao L, Metzger JM, Strack AM, Camacho RE, Mellin TN, Nunes CN, Min W, Fisher J, Gopal-Truter S, MacIntyre DE, Chen HY, et al. (2000) Inactivation of the mouse melanocortin-3 receptor results in increased fat mass and reduced lean body mass. Nat Genet 26:97-102.

Choi S, Wong LS, Yamat C, Dallman MF (1998) Hypothalamic ventromedial nuclei amplify circadian rhythms: do they contain a food-entrained endogenous oscillator? J Neurosci 18:3843-3852.

Chou TC, Scammell TE, Gooley JJ, Gaus SE, Saper CB, Lu J (2003) Critical role of dorsomedial hypothalamic nucleus in a wide range of behavioral circadian rhythms. J Neurosci 23:10691-10702.
Cone RD (2005) Anatomy and regulation of the central melanocortin system. Nat Neurosci 8:571-578.

Cone RD (2006) Studies on the physiological functions of the melanocortin system. Endocr Rev 27:736-749.

Dudley CA, Erbel-Sieler C, Estill SJ, Reick M, Franken P, Pitts S, McKnight SL (2003) Altered patterns of sleep and behavioral adaptability in NPAS2 deficient mice. Science 301:379-383.

Duez H, Staels B (2007) Rev-erbalpha gives a time cue to metabolism. FEBS Lett.

Elia M, Livesey G (1988) Theory and validity of indirect calorimetry during net lipid synthesis. Am J Clin Nutr 47:591-607.

Ellacott KL, Murphy JG, Marks DL, Cone RD (2007) Obesity-induced inflammation in white adipose tissue is attenuated by loss of melanocortin-3 receptor signaling. Endocrinology 148:6186-6194.

Feillet CA, Ripperger JA, Magnone MC, Dulloo A, Albrecht U, Challet E (2006) Lack of food anticipation in Per2 mutant mice. Curr Biol 16:2016-2022.

Fekete C, Marks DL, Sarkar S, Emerson CH, Rand WM, Cone RD, Lechan RM (2004) Effect of Agouti-related protein in regulation of the hypothalamic-pituitary-thyroid axis in the melanocortin 4 receptor knockout mouse. Endocrinology 145:4816-4821.

Fuller PM, Lu J, Saper CB (2008) Differential rescue of light- and foodentrainable circadian rhythms. Science 320:1074-1077.

Gooley JJ, Schomer A, Saper CB (2006) The dorsomedial hypothalamic nucleus is critical for the expression of food-entrainable circadian rhythms. Nat Neurosci 9:398-407.

Haskell-Luevano C, Chen P, Li C, Chang K, Smith MS, Cameron JL, Cone RD (1999) Characterization of the neuroanatomical distribution of agoutirelated protein immunoreactivity in the rhesus monkey and the rat. Endocrinology 140:1408-1415.

Hill JO (2006) Understanding and addressing the epidemic of obesity: an energy balance perspective. Endocr Rev 27:750-761.

Johnstone LE, Fong TM, Leng G (2006) Neuronal activation in the hypothalamus and brainstem during feeding in rats. Cell Metab 4:313-321.

King BM (2006) The rise, fall, and resurrection of the ventromedial hypothalamus in the regulation of feeding behavior and body weight. Physiol Behav 87:221-244.

Kohsaka A, Bass J (2007) A sense of time: how molecular clocks organize metabolism. Trends Endocrinol Metab 18:4-11.

Kornmann B, Schaad O, Bujard H, Takahashi JS, Schibler U (2007) Systemdriven and oscillator-dependent circadian transcription in mice with a conditionally active liver clock. PLoS Biol 5:e34.

Landry GJ, Simon MM, Webb IC, Mistlberger RE (2006) Persistence of a behavioral food-anticipatory circadian rhythm following dorsomedial hypothalamic ablation in rats. Am J Physiol Regul Integr Comp Physiol 290:R1527-1534.

Landry GJ, Yamakawa GR, Webb IC, Mear RJ, Mistlberger RE (2007) The dorsomedial hypothalamic nucleus is not necessary for the expression of circadian food-anticipatory activity in rats. J Biol Rhythms 22:467-478.

Laposky A, Easton A, Dugovic C, Walisser J, Bradfield C, Turek F (2005) Deletion of the mammalian circadian clock gene BMAL1/Mop3 alters baseline sleep architecture and the response to sleep deprivation. Sleep 28:395-409.

Liu C, Li S, Liu T, Borjigin J, Lin JD (2007) Transcriptional coactivator PGC-1alpha integrates the mammalian clock and energy metabolism. Nature 447:477-481.

Marsh DJ, Hollopeter G, Huszar D, Laufer R, Yagaloff KA, Fisher SL, Burn P, Palmiter RD (1999) Response of melanocortin-4 receptor-deficient mice to anorectic and orexigenic peptides. Nat Genet 21:119-122.

Mieda M, Williams SC, Richardson JA, Tanaka K, Yanagisawa M (2006) The dorsomedial hypothalamic nucleus as a putative food-entrainable circadian pacemaker. Proc Natl Acad Sci U S A 103:12150-12155.

Mistlberger RE (1994) Circadian food-anticipatory activity: formal models and physiological mechanisms. Neurosci Biobehav Rev 18:171-195.

Rahmouni K, Haynes WG, Morgan DA, Mark AL (2003) Role of melanocortin-4 receptors in mediating renal sympathoactivation to leptin and insulin. J Neurosci 23:5998-6004.

Reick M, Garcia JA, Dudley C, McKnight SL (2001) NPAS2: an analog of clock operative in the mammalian forebrain. Science 293:506-509.

Roselli-Rehfuss L, Mountjoy KG, Robbins LS, Mortrud MT, Low MJ, Tatro JB, Entwistle ML, Simerly RB, Cone RD (1993) Identification of a receptor for gamma melanotropin and other proopiomelanocortin peptides in 
the hypothalamus and limbic system. Proc Natl Acad Sci U S A 90:8856-8860.

Rossi M, Kim MS, Morgan DG, Small CJ, Edwards CM, Sunter D, Abusnana S, Goldstone AP, Russell SH, Stanley SA, Smith DM, Yagaloff K, Ghatei MA, Bloom SR (1998) A C-terminal fragment of Agouti-related protein increases feeding and antagonizes the effect of alpha-melanocyte stimulating hormone in vivo. Endocrinology 139:4428-4431.

Rutter J, Reick M, McKnight SL (2002) Metabolism and the control of circadian rhythms. Annu Rev Biochem 71:307-331.

Saper CB, Lu J, Chou TC, Gooley J (2005) The hypothalamic integrator for circadian rhythms. Trends Neurosci 28:152-157.

Singru PS, Sánchez E, Fekete C, Lechan RM (2007) Importance of melanocortin signaling in refeeding-induced neuronal activation and satiety. Endocrinology 148:638-646.

Staels B (2006) When the Clock stops ticking, metabolic syndrome explodes. Nat Med 12:54-55; discussion 55.

Stephan FK (2002) The "other" circadian system: food as a Zeitgeber. J Biol Rhythms 17:284-292.

Sutton GM, Trevaskis JL, Hulver MW, McMillan RP, Markward NJ, Babin
MJ, Meyer EA, Butler AA (2006) Diet-genotype interactions in the development of the obese, insulin-resistant phenotype of C57BL/6J mice lacking melanocortin-3 or -4 receptors. Endocrinology 147:2183-2196.

Tolle V, Low MJ (2008) In vivo evidence for inverse agonism of Agoutirelated peptide in the central nervous system of proopiomelanocortindeficient mice. Diabetes 57:86-94.

Trevaskis JL, Butler AA (2005) Double leptin (Lepob) and melanocortin-4 receptor $(\mathrm{Mc} 4 \mathrm{r})$ gene mutations have an additive effect on fat mass, and are associated with reduced effects of leptin on weight loss and food intake. Endocrinology 146:4257-4265.

van den Top M, Lee K, Whyment AD, Blanks AM, Spanswick D (2004) Orexigen-sensitive NPY/AgRP pacemaker neurons in the hypothalamic arcuate nucleus. Nat Neurosci 7:493-494.

Zhang Y, Kilroy GE, Henagan TM, Prpic-Uhing V, Richards WG, Bannon AW, Mynatt RL, Gettys TW (2005) Targeted deletion of melanocortin receptor subtypes 3 and 4, but not CART, alters nutrient partitioning and compromises behavioral and metabolic responses to leptin. FASEB J 19: 1482-1491. 